\title{
Marketing de Relacionamento junto a Consumidores Finais: um Estudo Exploratório com Grandes Empresas Brasileiras
}

\author{
André Cauduro D' Angelo \\ Heleno Schneider \\ Juliano Aita Larán
}

\begin{abstract}
RESUMO
O marketing de relacionamento é uma filosofia empresarial que prevê a construção e a manutenção de relacionamentos individuais com os clientes, vislumbrando um horizonte de longo prazo. Seja em mercados corporativos, seja naqueles voltados ao consumidor final, sua adoção demanda o engajamento da organização em uma postura cultural, estratégica e operacional que se coadune com seus princípios. Este artigo descreve e analisa a postura de grandes empresas brasileiras para desenvolver relacionamentos com consumidores finais, tomando como ponto de partida as prescrições da literatura dominante a respeito do tema. Os resultados, obtidos a partir de 19 entrevistas de profundidade, indicam que as empresas enfrentam dificuldades em todas as instâncias do marketing de relacionamento. Apesar de demonstrarem consciência de sua importância, não foram capazes ainda de inseri-lo na cultura e na estratégia organizacionais, depositando maior atenção às ferramentas operacionais. $\mathrm{O}$ artigo analisa as possíveis causas dessas dificuldades $\mathrm{e}$ sugere uma reflexão acerca de pertinência da produção acadêmica predominante nesse campo do Marketing.
\end{abstract}

Palavras-chave: marketing de relacionamento; cultura organizacional; estratégia; operação.

\begin{abstract}
Relationship marketing is a corporative philosophy that aims at building and keeping long-term individual relationships with clients. In corporative and customer markets it demands cultural, strategic and operational actions aligned with its principles. This article describes and analyzes how big Brazilian companies are developing relationships with final customers vis-à-vis the theory-in-use recommendations. The results - obtained through 19 in-depth interviews - indicate that companies use relationship marketing in a partial way, having difficulties in all of its dimensions. Despite the fact that companies are aware of its importance, they are not able to insert relationship marketing into their organizational culture and strategy, putting more importance on operational tools. The article analyses the possible causes for the identified gaps, and suggests reviewing the relevance of the theory-in-use of this Marketing field.
\end{abstract}

Key words: relationship marketing; organizational culture; strategy; operation. 


\section{INTRODUÇÃO}

O marketing de relacionamento emergiu, nas últimas duas décadas, como um dos mais promissores campos de investigação do Marketing. Ao mesmo tempo, tornou-se alvo de grande interesse gerencial, visto que suas práticas têm por objetivo conduzir as empresas a melhores resultados por meio do desenvolvimento de relacionamentos de longo prazo.

Este artigo tem como objetivo descrever e analisar a postura das grandes empresas brasileiras para a criação e sustentação de relacionamentos com consumidores finais, em face das prescrições da literatura dominante a respeito do tema. Para tanto, foi realizado um estudo exploratório, composto de entrevistas de profundidade com 19 das maiores empresas brasileiras de quatro ramos de atividade.

Parcela significativa da importância deste artigo reside no fato de que investigações sobre marketing de relacionamento em mercados de consumo final são menos comuns do que aquelas voltadas ao mercado corporativo, a despeito da crescente importância que o conceito vem assumindo junto a executivos dos chamados setores B2C (business-to-consumer). Além disso, o artigo tem como contribuição propor-se a analisar as ações empresariais, tendo como referencial a abordagem acadêmica dominante sobre marketing de relacionamento, promovendo a análise das práticas gerenciais vigentes e endereçando uma reflexão sobre a própria produção teórica desse campo do Marketing.

A estrutura do artigo é a que segue: inicia-se pela fundamentação teórica referente a marketing de relacionamento, apresenta-se o método de pesquisa utilizado e os resultados do estudo. A seguir, provê-se uma discussão dos resultados e sugerem-se investigações futuras para o campo do marketing de relacionamento.

\section{Fundamentação Teórica: Marketing de Relacionamento}

O marketing de relacionamento constitui um esforço integrado das empresas para identificar, construir, manter e aprimorar relacionamentos individuais com clientes, em um processo de troca de benefícios voltado para o longo prazo (Berry, 2002; Parvatiyar \& Sheth, 2000). Não se trata, portanto, de simplesmente 
desenvolver ações promocionais a partir de um banco de dados; tampouco mover esforços de retenção (Parvatiyar \& Sheth, 2000). Entendido de forma abrangente, o marketing de relacionamento tende a confundir-se com o próprio conceito de marketing, tornando-se sua espécie de síntese para os dias atuais (Gummesson, 2002; Palmer, 2002; Parvatiyar \& Sheth, 2000).

Seu surgimento, assim como a própria ascensão do marketing enquanto filosofia organizacional, origina-se de uma evolução natural das práticas empresariais e da configuração dos mercados, que tendem a jogar para a frente as fronteiras que regem a competição (Palmer, 2002; Parvatiyar \& Sheth, 2000). Como tantos outros conceitos que se popularizam nos meios acadêmicos e executivos, os princípios do marketing de relacionamento acabaram confundidos com práticas de natureza eminentemente operacional (Gummesson, 2002), cujo papel não passaria de apoio a uma cultura e a uma estratégia de negócio estruturalmente firmadas. Foi o que aconteceu com a gestão de banco de dados (database management, o DBM) e o CRM (Customer Relationship Management, ferramenta tecnológica que auxilia a implementação do marketing de relacionamento): de peças da engrenagem, acabaram confundidos com a própria engrenagem.

Embora originalmente concebido como abordagem exclusivamente interorganizacional, aos poucos o marketing de relacionamento tornou-se proposição também para mercados voltados ao consumidor final (O’Malley \& Tynan, 2000). Nessa transição é que algumas das confusões se estabeleceram e, subitamente, passou-se a entender marketing de relacionamento apenas como retenção de clientes, programas de fidelidade, gestão de banco de dados e até como simples erguimento de barreiras à saída de clientes. Foram ignorados fundamentos como a orientação para o longo prazo, a construção de vínculos emocionais com os clientes, a tentativa de conhecimento mais aprofundado dos consumidores e o desenvolvimento de confiança e comprometimento entre as partes (Berry, 2002; O’Malley \& Tynan, 2000).

Os resultados, no entanto, não tardaram a aparecer. Erguer barreiras para a saída de clientes, tornando-os reféns da empresa; focar única e exclusivamente na sua retenção; e entender a gestão de banco de dados como único suporte necessário ao estabelecimento de relacionamentos não tendem a cumprir o objetivo principal do marketing de relacionamento nas organizações: a constituição de vantagens competitivas sustentáveis (Rowe \& Barnes, 1998). Por meio dessas práticas consegue-se, no máximo, gerar paridade de condições com concorrentes. O estabelecimento de relacionamentos verdadeiros, ancorados nos princípios do marketing de relacionamento, por outro lado, é capaz de oferecer essa vantagem às empresas (Day, 2000; Gruen, 1997; Rowe \& Barnes, 1998). Mas, para tanto, 
é preciso que exista uma combinação de elementos que remeta cada ação a um princípio fundamental, garantindo sinergia e reforço constante.

Essa combinação de elementos abarca o tangível e o intangível. Inclui crenças, valores, conhecimentos, habilidades e recursos diversos (Day, 2000) que se traduzem na chamada cultura empresarial e nas diretrizes estratégicas, estejam elas formalizadas ou não. Daí a afirmação de que, para a adoção do marketing de relacionamento, uma empresa deve apresentar-se madura; deve estar imbuída de ideal e de comprometimento com alguns princípios (apresentar uma cultura ou filosofia, portanto) que acabam entendidos como fundamentais para o sucesso do negócio, fazendo parte do seu plano de ação (a estratégia propriamente), para só então se ocupar em escolher e formatar os recursos necessários à implementação (a operação). Sem os dois primeiros componentes - cultura e estratégia - CRM, DBM, programas de fidelidade, entre outros, tornam-se atividades comprometidas com ações estanques e de impacto limitado.

Quais são então as dimensões fundamentais para avaliar o engajamento de uma organização no marketing de relacionamento? Colocados em ordem de importância e classificados em três categorias principais - cultura, estratégia e operação - seguem algumas indicações da literatura a respeito.

Cultura Organizacional. Marketing de relacionamento, como já foi visto, pode até ser interpretado como sinônimo moderno para as práticas ideais de marketing. O primeiro passo para sua adoção é o compromisso firme com os propósitos mais essenciais do marketing: a empresa existe para atender consumidores, satisfazendo suas necessidades e seus desejos (Slater, 1997). Este deve ser, portanto, o modelo mental que permeia toda a organização e que fornece entendimento do que é, em essência, o negócio da empresa (Crosby \& Johnson, 2002; Day, 2000, 2002), comprometendo-a com a criação contínua de valor e a redução ao máximo das diferenças entre o que querem os clientes e o que a empresa oferece (Woodruff, 1997). O marketing, antes de uma área funcional específica, deve tornar-se atividade de toda a organização (Gruen, 1997). Como reflexo do compartilhamento de crenças como essas, os sistemas de recompensa e de avaliação de desempenho são vinculados à criação de valor para o cliente (Day, 2002; Woodruff, 1997), e não a métricas financeiras simplesmente. A incapacidade de disseminar esses valores é que tem tornado o marketing de relacionamento mais forte na teoria do que na prática (Fournier, Dobscha, \& Mick, 1998).

Estratégia Organizacional. Nem todos os setores empresariais comportam ou justificam a adoção de práticas de relacionamento. O exame cuidadoso das características do mercado e dos clientes é que deve fornecer indicações quanto à pertinência da adoção de uma estratégia baseada em relacionamentos individuais 
(Berry, 2002; Crosby \& Johnson, 2000; Deadrick, Mcafee, \& Glassman, 1997). Em mercados de consumo final, produtos e serviços de alto envolvimento e caracterizados por demanda relativamente inelástica são os espaços ideais para a adoção do marketing de relacionamento (O’Malley \& Tynan, 2000). Se a análise do mercado indicar viabilidade e adequação, o passo seguinte é identificar quais produtos e clientes justificam ações de relacionamento (Fournier et al., 1998). O produto ou serviço central da empresa deve ser forte a ponto de permitir que se construa, em torno dele, uma série de agregações de valor que incentivem o relacionamento (Berry, 2002).

As capacitações necessárias para a elaboração e a implementação de uma estratégia de marketing de relacionamento estão associadas ao entendimento do comportamento do consumidor (Fournier et al., 1998). A empresa deve ser capaz de compreender como seus produtos e serviços são adquiridos e usados, além de identificar o que é valor para o cliente e quais as melhores oportunidades para criá-lo (Almquist, Heaton, \& Hall, 2002; Crosby \& Johnson, 2000, 2001; Fournier et al., 1998; Gruen, 1997). Uma vez consolidado, o relacionamento individual, torna-se uma unidade de análise a ser monitorada e estimulada ao longo do tempo, sendo a empresa organizada pelos relacionamentos, e não por produtos ou funções (Crosby \& Johnson, 2002; Day, 2000; Gruen, 1997; Srirojanant \& Thirkellm, 1998).

Consequiência direta da construção de uma cultura voltada para o cliente, o desenvolvimento de estratégias passa por uma gestão cuidadosa dos recursos humanos (Berry, 2002; Crosby \& Johnson, 2001; Srirojanant \& Thirkellm, 1998). Mais do que peça de retórica, a gestão de RH é ponto nevrálgico dos caminhos que o marketing de relacionamento pode percorrer numa empresa; a partir de sua adoção, clientes e funcionários passam a ser tratados como ativos da organização, pois o relacionamento de longo prazo com os primeiros depende do relacionamento de longo prazo com os últimos (Deadrick et al., 1997).

Operação. O desenvolvimento de uma estratégia empresarial amparada nos conceitos de marketing de relacionamento demanda quatro pilares operacionais de sustentação (Parvatiyar \& Sheth, 2000): o primeiro, utilização de processos que viabilizem algumas das ações de relacionamento, como a constituição de parcerias com fornecedores e outros membros da cadeia produtiva, e a integração das comunicações de marketing. O segundo, formação de uma infra-estrutura capaz de sustentar e garantir operacionalização dessas ações, como centrais de atendimento a clientes e sistemas de captação de informação (Srirojanant \& Thirkellm, 1998). O terceiro, ferramentas de análise que processem e distribuam informações relevantes acerca dos clientes e das atividades de marketing da empresa. Entre estas estão o CRM e tantos outros instrumentos, como o DBM 
e a $\mathrm{ABC}$ (activity-based costing). E, finalmente, métricas que permitam um acompanhamento do desempenho dos negócios - como o balanced scorecard, o EVA (economic value added) e índices de satisfação de clientes e parceiros.

Sinteticamente, pode-se avaliar a adesão de uma organização ao marketing de relacionamento examinando a maneira como está comprometida com seus princípios culturais, estratégicos e operacionais.

\section{MÉTOdo}

Em consonância com os propósitos exploratórios deste trabalho, optou-se por adotar uma abordagem qualitativa de pesquisa. A técnica utilizada foi a de entrevistas de profundidade, conduzidas a partir de um roteiro semi-estruturado que, ao mesmo tempo que garantia aderência a algumas questões fundamentais extraídas da revisão da literatura, abria a possibilidade de descobertas originais, a partir do discurso dos informantes.

No caso, os tópicos fundamentais constantes no roteiro foram as três dimensõeschave para implementação de marketing de relacionamento, já expostas na revisão da literatura. A intenção, ao contemplá-las no protocolo de entrevista, foi permitir que, independentemente da heterogeneidade da amostra no que diz respeito aos setores econômicos, se mantivesse aderência a um framework fundamental relacionado aos objetivos de pesquisa. O mesmo framework foi utilizado como referência, ver-se-á mais adiante, para a análise dos dados.

As atividades anteriores ao trabalho de campo consistiram em selecionar os setores identificados como suscetíveis à adoção dos princípios do marketing de relacionamento. De acordo com a literatura, o marketing de relacionamento é especialmente importante para prestadores de serviços contínuos (Berry, 1983, 2002), como serviços financeiros e utilities. Empresas que não são essencialmente prestadoras de serviços, mas que mantêm contato freqüente com seus clientes, também podem praticar o marketing de relacionamento em mercados voltados ao consumidor final. Incluem-se aqui empresas de mídia impressa e de varejo; estes últimos costumam relacionar-se com clientes assíduos por meio de cartões de fidelidade e outros mecanismos que permitem parcelamento de compras e garantem alguns benefícios a consumidores freqüentes (Berry, 2002; O'Malley \& Tynan, 2000).

A partir dessas considerações, oriundas da literatura, definiram-se como setoresalvo da pesquisa as seguintes indústrias: 
- Serviços financeiros (bancos, seguradoras, administradoras de cartões de crédito).

. Utilities (telefonia celular, telefonia fixa, energia elétrica).

Mídia impressa (jornais e revistas).

- Varejo (supermercados, lojas de departamento e de eletrodomésticos, redes de drogarias e empresas de comércio eletrônico).

. Transporte aéreo (aviação civil).

As empresas a serem contactadas foram extraídas da relação de Maiores e Melhores, da revista Exame (2002). Priorizou-se o contato com as maiores empresas de cada setor, pelo critério de faturamento, de acordo com a listagem da revista.

O contato inicial foi feito via telefone. Procurou-se verificar, nestes contatos, os informantes mais habilitados a prover as informações necessárias aos objetivos da pesquisa. Embora a princípio os gestores das áreas de marketing parecessem os mais adequados, muitas vezes as empresas alocavam profissionais em atividades específicas que, nas suas próprias visões, diziam respeito a relacionamento com clientes, como a administração de cartões de fidelidade, vendas ou pesquisa de mercado. A partir do contato telefônico, tomava-se conhecimento do informante a ser procurado e, a partir daí, via fax e e-mail, partia-se para a solicitação formal de participação na pesquisa.

Ao todo, foram realizadas 19 entrevistas de profundidade com os seguintes profissionais: gerentes de marketing (9); gerentes de relacionamento (2); gerentes de planejamento estratégico (2); gerentes de assinaturas (2); gerente de fidelização (1); gerente de vendas (1); gerente de pesquisa (1); gerente de planejamento de marketing (1).

As empresas entrevistadas pertenciam aos seguintes setores:

- Oito (8) empresas do setor de serviços financeiros (4 bancos comerciais, 3 seguradoras e uma administradora de cartão de crédito).

- Duas (2) empresas do setor de telecomunicações (ambas operadoras de telefonia móvel).

. Três (3) empresas do setor de mídia impressa (duas editoras de revistas e uma de jornais). 
- Seis (6) empresas do setor de varejo (2 redes de supermercados, uma loja de departamento, uma empresa de comércio eletrônico, uma rede de lojas de eletrodomésticos e uma rede de drogarias).

As empresas entrevistadas tinham, majoritariamente, sede em São Paulo. Das 19 entrevistas, somente 2 foram realizadas fora de São Paulo (ambas no Rio Grande do Sul). As entrevistas foram realizadas nos meses de janeiro e fevereiro de 2003.

As entrevistas realizadas foram transcritas e submetidas a uma análise de conteúdo (Bauer \& Gaskell, 2002). Os procedimentos analíticos adotados valeramse da divisão do texto em unidades significativas para análise - no caso, parágrafos - que foram resumidos (Bardin, 1977) e classificados de acordo com os três componentes fundamentais da adoção do marketing de relacionamento (cultura, estratégia e operação), constantes na literatura. Depois da análise individual de cada entrevista, os parágrafos relativos a cada um dos três componentes fundamentais foram reunidos, de modo a permitir uma síntese sobre aspectos culturais, estratégicos e operacionais do marketing de relacionamento nas empresas entrevistadas. Todos os procedimentos de síntese e classificação foram revisados pelos três pesquisadores envolvidos no estudo, de modo a garantir validade aos resultados da pesquisa (Lincoln \& Guba, 1985).

\section{Principais Resultados}

Os resultados serão divididos conforme a dimensão correspondente: cultura organizacional, estratégia e operação.

\section{Cultura Organizacional}

O marketing de relacionamento emergiu, entre outros motivos, como consequiência da alteração de foco das empresas da conquista de novos clientes para a manutenção dos já existentes (Sheth, 2002). Embora marketing de relacionamento não deva ser confundido com retenção pura e simples de clientes - muitas vezes operacionalizada por meio de impedimentos à saída do consumidor (Parvatyiar \& Sheth, 2000) - é possível afirmar que atentar para a importância da manutenção dos clientes atuais constitui um primeiro passo para uma futura adesão aos relacionamentos.

"O processo de retenção, como a empresa já tem uma carteira de clientes consolidada, é fundamental, é o foco. É muito caro você fazer com que esta carteira cresça, ela já 
tem um nível de saturação. Não que seja impossível o crescimento, mas as taxas são bem menores do que há alguns anos atrás. Por isso a retenção é fundamental(...)" (Empresa de mídia).

Dessa forma, assim como ingressar nos domínios do marketing de relacionamento exige mudanças culturais relativamente profundas, postar-se na sua ante-sala - ou seja, adotar processos declaradamente voltados à permanência do cliente - não demanda predicados menos robustos, visto que representa um rompimento de paradigmas também. Mas, da compreensão de que "conquistar um novo cliente custa de cinco a dez vezes mais do que manter um cliente atual" (Gummesson, 1994, p. 17) à inserção dessa mentalidade na cultura organizacional, muitas empresas precisam percorrer ainda um longo caminho.

"É uma mudança de cultura [...] Pode parecer simples, mas nem todas as empresas estão preparadas para trabalhar desta forma, até porque você tem um imediatismo de resultado, bem ou mal você tem que fazer isto, é um processo lento que você tem que fazer" (Seguradora).

"É muito difícil porque a empresa inteira tem que estar comprometida" (Banco).

Assim, mesmo essas instâncias 'pré-relacionamento' engatinham em termos culturais dentro das empresas entrevistadas. Há ciência de sua importância, e alguns esforços repetidos conferem respaldo às convicções firmadas. Mas as ações e o próprio comprometimento soam incompletos, conferindo uma impressão dúbia de não-adoção total dos princípios, situação percebida pelos próprios entrevistados.

"Você pode criar mecanismos de fidelização, você amarra o cara. Os bancos fazem isso, eu te dou um nó, põe débito automático... isso é um jeito. Agora, se você quer realmente fidelizar, ter esse cliente satisfeito, isso passa pelo comportamental. Alguma coisa que está fidelizada é uma coisa que está satisfeita, com a necessidade atendida. Eu acho que a gente está muito longe disso" (Banco).

Esse caráter dúbio fica mais evidente quando se verifica que, historicamente, a preocupação maior das empresas entrevistadas sempre foi quanto à conquista de novos clientes - a chamada aquisição, postura que indicava uma despretensão quanto ao desenvolvimento de relacionamentos. Ainda há empresas em que este foco predomina, fato exemplificado pela alocação de verbas de propaganda e promoção, por exemplo. A cultura baseada em conquistar novos clientes ainda está muito presente e dificulta a adesão aos princípios do marketing de relacionamento.

"Ainda que a empresa tenha um discurso de rentabilização e retenção, tu sentes por aí sinais de que de fato ela deu mais importância para a aquisição" (Empresa de telefonia). 
"Vou ser muito sincera pra você, o que é mais feito, o que é mais realizado, é a aquisição. Ainda o esforço está sendo muito em aquisição" (Seguradora).

"Hoje o processo de aquisição é mais importante. Pode até se pegar alguns números, a maior área é a área comercial, que seria a aquisição, até mesmo porque era assim que o mercado tradicionalmente funcionava. Aquisição sempre é o foco" (Seguradora).

Uma forma de observar a cultura vigente em uma organização está nas métricas de avaliação e de recompensa existentes. Presumivelmente, empresas orientadas para o relacionamento deveriam incluir entre os indicadores de desempenho a manutenção de clientes e o desenvolvimento gradual de relacionamentos. Métricas desse tipo, ao permearem toda a organização, dos mais altos estratos aos mais baixos, tenderiam a representar comprometimento e engajamento completo em uma cultura organizacional voltada ao marketing de relacionamento. Não é o que se observa. Poucas empresas utilizam métricas que levam em conta dimensões de relacionamento com clientes, prevalecendo métricas mais tradicionais, ligadas a faturamento e rentabilidade.

"A [empresa] trabalha com um sistema de bonificação, mas é baseado em resultados financeiros da empresa. Supõe-se que o resultado provenha de um resultado positivo de retenção de clientes, ou de uma conquista maior de clientes, mas não necessariamente está ligado a estes números" (Varejista).

A fragilidade das práticas pré-relacionais é conseqüência direta de uma nãoorientação para o cliente. Privilegia-se ainda uma visão centrada no produto, em suas linhas, extensões e administração. Mesmo que a prestação de serviços contínuos - caso da maior parte das empresas entrevistadas - ofereça a possibilidade de um aprofundamento do conhecimento e, conseqüientemente, da relação com o cliente, a ênfase em produtos fornece mais uma evidência de uma cultura ainda não voltada para o consumidor.

"Grande parte das empresas estão acostumadas a muito mais produto, rentabilidade por produto. (...) Entender que o fulano é o fulano e que ele tem um relacionamento agregando aqueles produtos, é diferente de você ter seguro de vida que está agregando tais e tais clientes. Isto é uma mudança de foco muito grande, eu diria que o grande problema, realmente, é cultura" (Seguradora).

\section{Estratégia Organizacional}

Se a cultura organizacional não se apresenta ainda como solidificada para o relacionamento - estando até a titubear em seus estágios introdutórios - a estratégia não deixa de refletir postura semelhante. O marketing de relacionamento é cabível em todas as empresas entrevistadas, em maior ou menor 
grau, devido às características do mercado de atuação. A interação freqüente com os consumidores enseja a acumulação de conhecimento e a geração de inteligência que, internamente geridos, poderiam produzir ações concretas no sentido do relacionamento. Não é o que se observa, contudo. Além dos limites impostos pela cultura, a implementação de estratégias de marketing de relacionamento é dificultada por outros fatores. Um deles é o foco no curto prazo. As ações de marketing contempladas no planejamento organizacional debruçam-se sobre objetivos e metas imediatistas, desprezando horizontes de tempo mais longos.

"Como a gente não sabe como esse cliente vai estar daqui um ano, a gente tem que rentabilizar ele na hora" (Varejista).

"Se você pegar um cara só de vendas, ele vai dizer que tem que vender, ele está sendo pressionado pela meta" (Seguradora).

Outro impedimento diz respeito à incapacidade de compreender o comportamento do consumidor, suas mudanças e porquês. Bancos de dados repletos são insuficientes para prover o conhecimento que um relacionamento demanda. Apesar da utilização de pesquisas de mercado, há também a dificuldade de relacionar informações obtidas por meio dessas pesquisas com aquelas presentes no banco de dados. Há um divórcio entre os dados armazenados e as demais fontes de informação dos clientes - pesquisas, empregados de linha de frente etc. - retirando inteligência e capacidade de ação das empresas.

"Hoje você tem, em algumas áreas urbanas, uma média de 10 supermercados, hiper, mercadinhos urbanos, em uma área, às vezes, de 10, 5 quilômetros quadrados. [Digamos que] eu moro bem no meio, estou eqüidistante de pelo menos três. Por que eu vou aqui, ou lá ?" (Varejista).

"O que acontece que eu conheço o Fulano porque ele tem o carro tal, cinco geladeiras. A dificuldade é conhecer a pessoa pelo que ela é, qual a perspectiva de vida dela, nós podemos ter a mesma quantidade de bens e sermos pessoas completamente diferentes. Podemos ter a mesma faixa etária e eu posso ser voltada para a família, religiosa, e você ser um rebelde aventureiro" (Empresa de mídia).

A fragilidade das estratégias evidencia-se quando, desprovidas de análises mais profundas, algumas empresas consideram que todos seus serviços e clientes devem ser englobados pelas estratégias de marketing de relacionamento, desprezando eventuais diferenças e possíveis impedimentos a essas práticas. Outras se mostram mais cautelosas quanto ao potencial de relacionamento, indicando já terem superado esse estágio e hoje se mostram mais seletivas quanto ao potencial existente. 
"Você fazer uma estratégia de sair e conquistar cliente um a um, para uma segmentação mais alta de renda, isso é até razoável; mas para uma segmentação de baixa renda o custo não compensa porque tem outros meios mais baratos" (Banco).

Outro ponto essencial ao desenvolvimento de uma estratégia de marketing de relacionamento é a gestão cuidadosa de recursos humanos. Apesar disso, poucas empresas parecem atentar para este aspecto, sem vislumbrar correspondência entre uma adequada gestão de RH e os objetivos estratégicos traçados pela empresa.

"Você envolver e comprometer pessoas é muito complicado. Acho que isso passa por uma política. Acho que as empresas precisam primeiro começar a tratar mais [do funcionário]. Se você quer que o seu cliente seja atendido dessa forma, o seu funcionário tem que ser atendido dessa forma e às vezes as empresas se esquecem do funcionário" (Banco).

\section{Operação}

Uma vez que o engajamento cultural e estratégico das empresas no marketing de relacionamento é apenas parcial, apresentando desnível de comprometimento entre diferentes práticas, os reflexos dessa situação naturalmente aparecem quando se trata da operação. Dos quatro pilares operacionais que sustentam as estratégias de marketing de relacionamento - processos, infra-estrutura, ferramentas de análise e métricas - as empresas entrevistadas parecem dar mais atenção a dois deles: infra-estrutura e ferramentas de análise. Coincidentemente, são os dois menos dependentes de formação de uma cultura e uma estratégia adequadas, pois para sua adoção basta a aquisição de pacotes prontos de tecnologia.

Tentativas de implementar uma filosofia de marketing de relacionamento enfocando simplesmente aspectos operacionais e tecnológicos não são bem sucedidas ou, no mínimo, têm alcance muito limitado. Essa consciência já parece emergir em algumas empresas que, embora não adotem com profundidade os pressupostos do marketing de relacionamento, consideram um erro ignorar aspectos culturais e estratégicos.

"Toda esta parte de ferramentas, ela só vem ajudar mais quando você está com alguma estratégia, toda esta parte acertadinha" (Seguradora).

Quanto à infra-estrutura, centrais de atendimento aparecem na maioria das empresas, mas sem a necessária alimentação de informações em tempo real. Uma divisão comum das centrais de atendimento é a separação em setores especializados: um para a conquista e outro para manutenção de clientes. 
Enquanto em algumas empresas os processo de conquista e manutenção de clientes estão pulverizados por diversas áreas, em outras existem áreas específicas para tratar de cada um deles. Nestes casos estas áreas geralmente estão vinculadas ao departamento de marketing, que, muitas vezes, é responsável também pela operacionalização dos processos. Para essas atividades, contam com o apoio de outras áreas, comumente de tecnologia da informação (TI), principalmente no tocante a banco de dados. A função de marketing, assim, é distribuída em setores diversos, mas não num sinal de disseminação da orientação para o cliente e para relacionamentos, e sim, devido à comodidade operacional oferecida: profissionais de tecnologia e informática administram ferramentas que, do ponto de vista estritamente funcional, dizem respeito às suas competências, independentemente das finalidades da sua adoção.

Boa parte das ações das empresas é baseada em análise de banco de dados, por meio de datamining ou de outros processos mais simples. Ferramentaspadrão são a tônica entre elas, mesmo as de CRM. Em relação ao CRM, nenhuma parece ter desenvolvido plenamente seu potencial tal como se apregoa na literatura.

"A gente monta planos homéricos de retenção e de aquisição, mas você esbarra em sistema de atendimento, no sistema de contato com o cliente. É muito triste quando você monta um plano para o cliente e quando ele entra na internet a gente não consegue nem saber quem é ele" (Empresa de mídia).

"Se fala muito de CRM, CRM, mas poucas vezes a empresa realmente está capaz de praticar. A gente está a caminho dele, mas ainda falta... A dificuldade que eu tenho é a de integrar todas as informações que eu tenho e que estão separadas" (Banco).

De modo geral, apesar das propaladas virtudes das ferramentas que sustentam o marketing de relacionamento, a incerteza predomina entre os gestores entrevistados. A incapacidade de afirmar, de maneira peremptória, a validade de utilização desses instrumentos advém da incipiência das ações e da própria inexistência de casos práticos comprovadamente bem-sucedidos.

"Eu acho que ninguém ainda chegou lá, está todo mundo tentando. Existem técnicas, mas a comprovação efetiva dos resultados que essas técnicas podem proporcionar, você tem [apenas] alguns cases... Eu acho que tem muito que avançar" (Banco).

"Estamos lidando com conceitos não comprovados; ninguém sabe o que está certo ou o que está errado" (Empresa de telefonia).

“(...) Qual é o resultado efetivo que isso dá? Porque é muito bonito você fazer CRM, datawarehouse, database, não sei o quê... é muito bonito ter isso, mas qual o resultado? O resultado que você está tendo, isso aumentou receita? E qual o custo que isso teve? (...) Onde está o resultado efetivo?" (Banco). 
Em síntese, poder-se-ia afirmar que as empresas se mostram parcialmente comprometidas no marketing de relacionamento em suas três dimensões cultural, estratégica e operacional -, fato que conduz a ações descontinuadas e de impacto limitado.

\section{Discussão}

Se fôssemos imaginar o marketing de relacionamento como o extremo de um continuиm, como sugere Grönroos (1994) - em que no outro extremo estaria o marketing transacional - poderíamos dizer que a maior parte das empresas entrevistadas no presente trabalho se situa em posição intermediária, guardando ainda uma distância considerável do extremo relacional. A razão dessa localização reside no caráter parcial que o marketing de relacionamento assume nas organizações pesquisadas. Se não, vejamos.

. Os gestores mostram consciência da importância do marketing de relacionamento, mas reconhecem a dificuldade de elevá-lo à condição de constituinte da cultura e dos valores de suas empresas. Contentam-se, por enquanto, em desenvolver projetos específicos que, a despeito da relação que guardam com as atividades centrais da empresa, apresentam impacto limitado.

- A condição de elemento estratégico global das empresas ainda é restrita; o marketing de relacionamento mostra-se tão somente como objetivo do marketing ou de áreas correlatas, carecendo ainda de alguns pré-requisitos importantes para sua implementação, como o conhecimento do comportamento dos clientes, por exemplo.

- As ferramentas tecnológicas são utilizadas de maneira ainda restrita, sem domínio absoluto das suas potencialidades. Figuram em alguns casos como elemento fundamental, ignorando seu papel de mero suporte.

Há, assim, um marketing de relacionamento parcial nas dimensões cultural, estratégica e operacional das organizações. Como visões limitadas do que constitui o relacionamento com clientes costumam depositar na operação a responsabilidade de condução do processo, fracassos nessa dimensão acarretam desestímulos para as demais. Ignora-se muitas vezes que a tecnologia é apenas o passo final de um processo que começa com a cultura e passa pela estratégia.

Day (2002) observou fato semelhante em algumas empresas norte-americanas, vislumbrando nessa distorção um indicador das próprias dificuldades que os gestores enfrentam ao analisar o mercado e seus concorrentes. Segundo os 
gestores entrevistados em seu estudo, investimentos em tecnologia e ferramentas de banco de dados justificavam-se pela facilidade que representavam para as empresas em se manter equiparadas aos seus concorrentes. Desconhecendo detalhes mais profundos das estratégias desenvolvidas por outras corporações, os executivos enxergavam nos ferramentais tecnológicos uma referência de comparação essencial na tentativa de sustentar a competitividade de suas organizações.

É possível que motivação semelhante tenha acometido as empresas brasileiras; estimuladas por ambientes de negócios que valorizam a velocidade e a permanente atenção aos passos dos competidores, e submetidas a um contingente elevado de modismos gerenciais que ganham status de panacéia, é razoável supor que por vezes o acompanhamento do mercado permaneça na superfície e que nele sejam forjadas muitas decisões. A reafirmação periódica da necessidade de ação, apoiada na emergência de um mercado milionário na área de sistemas de tecnologia - CRM, especialmente - contribui para gerar inseguranças generalizadas que, na intenção de serem minoradas, inevitavelmente desembocam numa decisão: investir. Dessa forma, por trás da implementação do marketing de relacionamento tende a residir uma amostra das características do ambiente empresarial contemporâneo.

Vale destacar também que o marketing de relacionamento não emergiu nos meios acadêmicos de modo alheio ao contexto sociocultural de sua época; não se originou de fatores essencialmente empresariais, portanto. $\mathrm{Na}$ verdade, entre os impulsionadores de seu surgimento e ascensão estiveram elementos que figuravam na promoção de um novo paradigma social, ancorado mais na cooperação e menos na competição (Palmer, 2002). Relacionamento com clientes é uma forma de cooperação entre empresas e consumidores. Por isso é inegável que o relacionamento com clientes é também função de uma postura de relacionamentos da organização com outros stakeholders, especialmente fornecedores. De uma postura essencialmente competitiva, passa-se a uma colaborativa, o que representa mudança de paradigma que, se não é absorvida, dificilmente faz prosperar qualquer iniciativa nesse campo.

A colaboração entre empresas e fornecedores dá-se especialmente em setores industriais, fortalecendo o chamado relacionamento B2B (business-tobusiness), cujos principais exemplos estão na indústria automobilística. No setor de serviços, que compõe a maior parte da amostra da presente pesquisa, relacionamentos com fornecedores são uma possibilidade mais remota. Como conseqüência, as empresas entrevistadas podem estar ressentindo-se da falta de experiência em relacionamentos $\mathrm{B} 2 \mathrm{~B}$, o que lhes facilitaria, a despeito das inúmeras diferenças, a implementação do relacionamento B2C. Se as próprias 
relações B2B são por vezes difíceis e penosas, é natural que as dificuldades se agravem na tentativa de levar a cabo relações mais sofisticadas, como no B2C.

Um aspecto que corrobora a magnitude do desafio do relacionamento B2C é que nele, especialmente, elementos que não são puramente funcionais tomam grande importância. Erram as empresas que entendem o relacionamento como sinônimo de retenção de clientes ou mera repetição de compra; se assim se portarem, estarão desprezando a dimensão emocional do relacionamento, aquela que une empresa e clientes por razões que excedem motivações exclusivamente funcionais. Desses benefícios extrafuncionais é que se originam os principais resultados do relacionamento: propaganda boca a boca e fidelidade do cliente (Hennig-Thurau, Gwinner, \& Gremler, 2002).

A compreensão de questões emocionais envolvidas num relacionamento só ocorre a partir de capacitações bem desenvolvidas em entendimento do comportamento do cliente, quesito no qual as empresas entrevistadas se mostram vacilantes. As conseqüências dessas dificuldades não são pequenas: distanciarse dos consumidores leva as empresas a 'agregar valor' por meio de atributos e benefícios de pouca representatividade para os clientes, esquecendo que, na lógica do marketing de relacionamento, o próprio relacionamento impacta a percepção de valor (Ravald \& Grönroos, 1996). Valor e benefícios, numa perspectiva de longo prazo e relacional, assumem para os clientes significados diferentes daqueles comuns em transações, porque envolvem confiança e comprometimento (Ravald \& Grönroos, 1996). Os clientes passam a perceber a empresa não só como provedora de vantagens relativas ao produto, mas de vantagens relacionais que pesam na sua escolha (Day \& Van Den Bulte, 2002). A empresa passa também a administrar relacionamentos, e não só produtos - e a própria segmentação dos clientes em relacionais e transacionais acaba refletindo essa realidade (Sheth, 2002).

Em suma, as entrevistas mostraram um descompasso significativo entre o que prescreve a literatura dominante em marketing de relacionamento e as práticas das empresas entrevistadas. Embora ao longo deste tópico de discussão se tenha priorizado uma análise voltada à prática corporativa, convém não esquecer que tais resultados merecem suscitar também reflexões relacionadas à produção teórica desse campo do Marketing. Por se tratar de disciplina aplicada, a validade da teoria gerada em Marketing é constantemente submetida ao crivo da aplicação prática; discute-se sempre se o conhecimento acadêmico produzido é aplicável do ponto de vista gerencial (Grönhaug, 2002; Razzaque, 1998). Nesse contexto, as dificuldades de implementação e de obtenção de resultados com o marketing de relacionamento justificam questionamentos quanto aos fundamentos teóricos que o sustentam, de modo que é possível enxergar o divórcio entre teoria dominante 
e prática mais como deficiência da primeira do que da segunda. O mesmo relevo que nesta pesquisa se depositou sobre as atividades empresariais deve ser empregado numa reflexão dos acadêmicos de Marketing a respeito da teoriaem-uso nesta área de estudos.

\section{Limitações e Futuras Pesquisas}

O presente estudo apresenta como principal limitação a óbvia impossibilidade de generalização de seus resultados. O número de entrevistas realizadas e o caráter qualitativo da investigação impedem que os resultados aqui verificados sejam extrapolados ao universo das grandes corporações brasileiras.

Da mesma forma, apesar de ancorada na literatura, a abrangência setorial das empresas entrevistadas excluiu um ramo importante: as indústrias. Parcela expressiva das grandes corporações nacionais é desse ramo de atividade e convém atentar que, embora não se trate de um setor afeito às práticas de relacionamento $\mathrm{B} 2 \mathrm{C}$, não é prudente descartar que existam empresas que estejam procurando, de alguma maneira, engajar-se em ações dessa natureza.

Além disso, a realização de uma pesquisa baseada em entrevistas com um representante de cada empresa é passível de viés, visto que se vale somente de uma visão quanto à posição da organização no que tange ao tema abordado. A realização de mais de uma entrevista por empresa, ou mesmo a consulta a outras fontes de evidência - como documentos, relatórios, matérias de imprensa diminuiria a dependência em relação ao relato de um único informante, permitindo que se confrontassem informações e percepções.

Quanto às pesquisa futuras, é relevante que se promovam estudos voltados ao exame da pertinência da produção acadêmica relativa a marketing de relacionamento. Aqui, nesta pesquisa, trabalhou-se basicamente com uma comparação entre o que recomenda a teoria acadêmica dominante e aquilo que as empresas, de fato, têm realizado, apontando os principais gaps existentes entre um e outro. Ao se adotar esta premissa, teve-se como consequiência lógica uma análise focada quase exclusivamente na adequação ou não das corporações entrevistadas aos princípios majoritariamente previstos na literatura.

Ainda assim, é possível analisar os resultados desta pesquisa por outro ângulo, priorizando não uma reflexão sobre a prática corporativa, mas sobre a teoria dominante em marketing de relacionamento. Ao mesmo tempo que se pode enxergar uma inadequação das empresas às prescrições teóricas, pode-se fazer 
o caminho inverso, apontando a incapacidade da teoria-em-uso de descrever o comportamento de empresas e consumidores.

Nesse sentido, Coviello e Brodie (1998) oferecem uma contribuição que pode ser de grande proveito em futuros estudos. Gestores entrevistados por eles mostraram apoio e concordância com os princípios conceituais do marketing de relacionamento, mas foram cautelosos e reticentes quanto à aplicação de vários deles. Diferenças entre os mercados, limitações de ordem organizacional e circunstâncias diversas foram consideradas como impedimentos à consecução de muitos dos pilares do marketing de relacionamento. Ademais, os gestores indicaram a necessidade de que fosse analisada a relação custo-benefício das ações de marketing de relacionamento, de modo a atestar, por meio de métricas confiáveis, sua verdadeira relevância. Análises como essa dão a entender que possivelmente a literatura predominante em marketing de relacionamento desconsidere as múltiplas realidades mercadológicas e empresariais, reduzindo um fenômeno complexo como o marketing a uma série de prescrições inaplicáveis na sua totalidade.

Um exemplo nesse sentido vem da própria oposição entre trocas transacionais e relacionais, freqüentemente mencionada na literatura. Ocupando as extremidades de um continuum, estes dois conceitos são tratados como opostos totais, não só por sua posição, como também por seu valor: defende-se que se deve buscar um extremo (relacional) e distanciar-se do outro (transacional). $\mathrm{Na}$ verdade, pouco se tem cogitado da possibilidade de que transações e relacionamentos possam coexistir, freqüentemente numa mesma indústria e empresa, por responderem às necessidades das partes envolvidas - organização e consumidor (Coviello \& Brodie, 1998; Fitchett \& Mcdonagh, 2000). Ambos podem ser, cada um a seu tempo e circunstância, caminhos eficazes à consecução de objetivos organizacionais e individuais.

Da mesma forma, ainda reconhecendo que, se a lógica que sustenta o marketing de relacionamento reside na colaboração (Gummesson, 1997), não se pode esquecer que comportamentos oportunistas e não-colaborativos podem constituir caminho natural para a eficácia econômica em muitos setores (Coviello \& Brodie, 1998), o que invalidaria também o caráter universal de uma prescrição dessa ordem.

Assim, é pertinente que pesquisas futuras invertam a lógica de análise realizada neste artigo, e examinem com espírito crítico não só as práticas empresariais, mas principalmente a relevância da teoria dominante em marketing de relacionamento.

\section{Artigo recebido em 03.03.2004. Aprovado em 30.10.2004.}




\section{Referências Bibliográficas}

Almquist, E.,

Heaton, C., \&

Hall, N. (2002, June).

Making CRM make money. Marketing

Management, 11(3), 17-21.

Bardin, L. (1977).

Análise de conteúdo. Lisboa: Edições 70.

Bauer, M. W., \&

Gaskell, G. G. (2002).

Pesquisa qualitativa com texto, imagem e som. Petrópolis, RJ: Vozes.

Berry, L. (1983).

Relationship marketing. In: L. Berry, L. Shostack, \& G. Upah. Emerging perspectives on services marketing. Chicago: American Marketing Association.

Berry, L. (2002).

Relationship marketing of services perspectives from 1983 and 2000. Journal of Relationship Marketing, 1(1), 59-77.

Coviello, N., \&

Brodie, R. (1998).

From transaction to relationship marketing. Journal of Strategic Marketing, 6(3), 171-186.

Crosby, L. A., \&

Johnson, S. L. (2000, Winter).

What to do before going 1-to-1. Marketing Management, 9(4), 15-21.

Crosby, L. A., \&

Johnson, S. L. (2001, September/October). High performance marketing in the
CRM era. Marketing Management, 10(3), 10-11.

Crosby, L. A., \&

Johnson, S. L. (2002, January/February). CRM and management. Marketing Management, 11(1), 10-11.

Day, G. S. (2000, Winter).

Managing market relationships. Journal of the Academy of Marketing Science, 28(1), 24-30.

Day, G. S. (2002, October).

Winning the competition for customer relationships. [working paper]. The Wharton School.

Day, G. S., \&

Van Den Bulte, C. (2002, September).

Superiority in customer relationship management: consequences for competitive advantage and performance [working paper]. The Wharton School.

Deadrick, D,

McAfee, B. \&

Glassman, M. (1997, July/August)

Customers for life: does it fit your culture? Business Horizons, 40(4), 1116.

Editora Abril (2002).

Revista Exame: melhores \& maiores. São Paulo. SP: Autor.

Fitchett, J., \&

McDonagh, P. (2000).

A citizen's critique of relationship marketing in risk society. Journal of Strategic Marketing, 8(2), 209-222. 
Fournier, S.,

Dobscha, S., \&

Mick, D. G. (1998, January/February).

Preventing the premature death of relationship marketing. Harvard Business Review, 76(1), 42-51.

Grönhaug, K. (2002).

Is marketing knowledge useful? European Journal of Marketing, 36(6), 364-372.

Grönroos, C. (1994).

From marketing mix to relationship marketing: towards a paradigm shift in marketing. Managerial Decision, 32(2), 4-20.

Gruen, T. W. (1997, November/December). Relationship marketing: the route to marketing efficiency and effectiveness. Business Horizons, 40(6), 32-38.

Gummesson, E. (1994).

Making relationship marketing operational. International Journal of Services Industry Management, 5(5), 5-20.

Gummesson, E. (1997).

Relationship marketing as a Paradigm Shift. Management Decision, 35(3-4), 267-273.

Gummesson, E. (2002).

Relationship marketing in the new economy. Journal of Relationship Marketing, 1(1), 37-57.

Hennig-Thurau, T.,

Gwinner, K. P., \&

Gremler, D. D. (2002, February).

Understanding relationship marketing outcomes. Journal of Service Research, 4(3), 230-247.
Lincoln, Y., \&

Guba, E. (1985).

Naturalistic inquiry. London: Sage.

O’Malley, L. \&

Tynan, C. (2000).

Relationship marketing in consumer markets - rhetoric or reality? European Journal of Marketing, 34(7), 797-815.

Palmer, A. (2002).

The evolution of an idea: an environmental explanation of relationship marketing. Journal of Relationship Marketing, 1(1), 79-94.

Parvatiyar, A., \&

Sheth, J. (2000).

The domain and conceptual foundations of relationship marketing. In: J. Sheth, \& A. Parvatiyar. Handbook of relationship marketing. Thousands OAKS: Sage.

Raval, A.,

Grönroos, C. (1996).

The value concept and relationship marketing. European Journal of Marketing, 30(2), 19-30.

Razzaque, M. A. (1998, Winter).

Scientific method, marketing theory development and academic vs. practitioner orientation: a review. Journal of Marketing Theory \& Practice, 6(1), 1-15.

Rowe, W. G., \&

Barnes, J. G. (1998).

Relationship marketing and sustained competitive advantage. Journal of Market Focused Management, 3(2), 281-297. 
Sheth, J. (2002).

The future of relationship marketing. Journal of Services Marketing, 16(7), 590-592.

Slater, S. F. (1997, Spring).

Developing customer value-based theory of the firm. Journal of the Academy of Marketing Science, 25(2), 162-167.
Srirojanant, S., \&

Thirkell, P. C. (1998).

Relationship marketing and its synergy with web-based technologies. Journal of Market Focused Management 3(3), 23-46.

Woodruff, R. B. (1997, Spring).

Customer value: the next source for competitive advantage. Journal of the Academy of Marketing Science, 25(2), 139-153. 
